\section{Fra-1 replaces c-Fos-dependent functions in mice}

\author{
Alexander Fleischmann, ${ }^{1}$ Farhad Hafezi, ${ }^{2}$ \\ Candace Elliott, ${ }^{1}$ Charlotte E. Remé, ${ }^{2}$ \\ Ulrich Rüther, ${ }^{3}$ and Erwin F. Wagner ${ }^{1,4}$
}

\begin{abstract}
${ }^{1}$ Research Institute of Molecular Pathology (IMP), A-1030 Vienna, Austria; ${ }^{2}$ Department of Ophthalmology, University Clinic, 8091 Zurich, Switzerland; ${ }^{3}$ Entwicklungs- und Molekularbiologie der Tiere (EMT), Heinrich-HeineUniversität Düsseldorf, 40225 Düsseldorf, Germany
\end{abstract}

Structure-function analysis as well as studies with knock-out and transgenic mice have assigned distinct functions to c-Fos and Fra-1, two components of the transcription factor AP-1 (activator protein-1). To test whether Fra-1 could substitute for c-Fos, we generated knock-in mice that express Fra-1 in place of c-Fos. Fra-1 rescues c-Fos-dependent functions such as bone development and light-induced photoreceptor apoptosis. Importantly, rescue of bone cell differentiation, but not photoreceptor apoptosis, is gene-dosage dependent. Moreover, Fra-1 fails to substitute for c-Fos in inducing expression of target genes in fibroblasts. These results show that c-Fos and Fra-1 have maintained functional equivalence during vertebrate evolution.

Received August 17, 2000; revised version accepted September 21, 2000.

The dimeric transcription factor AP-1 (activator protein1) is composed of members of the Fos, Jun, and ATF family of proteins (Angel and Karin 1991). AP-1 activity is induced by a vast number of stimuli, including growth factors, cytokines, and UV irradiation, and couples cell surface signals to changes in cellular phenotype by regulating the expression of target genes (Angel and Karin 1991; Karin et al. 1997). Members of the AP-1 complex are critically involved in a multitude of cellular processes such as proliferation, differentiation, cell death, and oncogenic transformation. It has been hypothesized that the ability to regulate such a large number of biological processes is achieved by the formation of various functional dimers with distinct biological properties. Fos proteins (c-Fos, FosB, Fra-1, Fra-2) form stable dimers with Jun proteins (c-Jun, JunB, JunD), whereas Jun proteins can form homodimers and heterodimers with Fos and ATF proteins (Angel and Karin 1991; Karin et al. 1997).

c-Fos (encoded by Fos) and Fra-1 ( Fos-related antigen-1, encoded by the Fos-like-1 gene, Fosi1) show high homol-

[Key Words: AP-1; c-Fos; Fra-1; knock-in; mouse development] ${ }^{4}$ Corresponding author.

E-MAIL wagner@nt.imp.univie.ac.at; FAX 43-1-7989370.

Article and publication are at www.genesdev.org/cgi/doi/10.1101/ gad. 187900 . ogy in their leucine zipper and DNA-binding domains. Consistent with this sequence conservation, DNA binding specificity of Fra-1/c-Jun heterodimers is indistinguishable from c-Fos/c-Jun heterodimers (Cohen et al. 1989|. Outside these domains, the proteins show little similarity. Most importantly, Fra-1 lacks transactivation domains and fails to activate transcription when fused to the DNA-binding domain of Gal4. In contrast, c-Fos is a potent activator of transcription (Cohen et al. 1989). Interestingly, Fosl1 is a transcriptional target of c-Fos, and induction of Fos11 upon growth factor stimulation is delayed compared with Fos (Cohen and Curran 1988; Bergers et al. 1995; Schreiber et al. 1997; Matsuo et al. 2000). This led to the hypothesis that Fra-1 might counteract the function of c-Fos by lowering the transactivation potential of AP-1 complexes (Yoshioka et al. 1995).

Fosl1 and Fos show different yet partially overlapping expression patterns in mice. Fosl1 is expressed in extraembryonic tissues during mouse development and in brain, skin, and testes of adult mice (Schreiber et al. 1997, 2000). Fos is expressed in the placenta and in several organs of the embryo, including fetal liver, heart, brain, and developing bones. In adult mice, Fos is readily detectable in most tissues, with highest levels found in brain and bone (Smeyne et al. 1993). Gain-of-function experiments have shown that overexpression of Fra-1 leads to increased bone formation and osteosclerosis (Jochum et al. 2000), whereas overexpression of c-Fos results in osteo- and chondrosarcomas (Rüther et al. 1987; Wang et al. 1992). Targeted disruption of the Fos11 gene leads to early embryonic lethality due to impaired vascularization of the placenta (Schreiber et al. 2000). In contrast, lack of c-Fos results in pleiotropic defects, most importantly the bone disease osteopetrosis, due to the lack of bone-resorbing osteoclasts (Johnson et al. 1992; Wang et al. 1992; Grigoriadis et al. 1994). Furthermore, c-Fos-deficient photoreceptor neurons in the retina are resistant to light-induced apoptosis (Hafezi et al. 1997; Wenzel et al. 2000). These results suggest that c-Fos and Fra-1 have distinct functions in mice. On the other hand, Fosl1 is a transcriptional target of c-Fos in osteoclast progenitors, and overexpression of Fra-1 by viral gene transfer in vitro or in transgenic mice was able to rescue c-Fos-dependent osteoclast differentiation (Matsuo et al. 2000).

To test whether Fra-1 can take over c-Fos functions under physiological conditions, knock-in mice were generated in which Fos is deleted and replaced by Fosl1. Interestingly, Fosl1 can fully complement for the lack of c-Fos in bone development and substitutes for the proapoptotic function of c-Fos in photoreceptor neurons. Rescue of bone cell differentiation, but not photoreceptor apoptosis, is gene dosage dependent. Furthermore, Fra-1 fails to rescue the expression of c-Fos target genes in fibroblasts. These data suggest that transactivation by c-Fos might be dispensable in vivo and that stage- and cell-specific modulation of expression determines the specific functions of these genes. 


\section{Results}

Generation of Fos ${ }^{\text {Fosl1 }}$ knock-in mice

To generate Fos ${ }^{\text {Fos11 }}$ knock-in mice, we constructed a gene-targeting vector that upon homologous recombination causes the deletion of exon 1 and part of exon 2 of Fos and its replacement by the Fosl1 gene (Fig. 1a). Because Fos mRNA levels are controlled not only by promoter activity but also by destabilizing sequences in the $3^{\prime}$ untranslated region (UTR), these Fos sequences were left intact. The construct was introduced into embryonic stem (ES) cells, and correctly targeted clones were identified by polymerase chain reaction (PCR) and Southern blotting. After Cre-mediated deletion of the selection
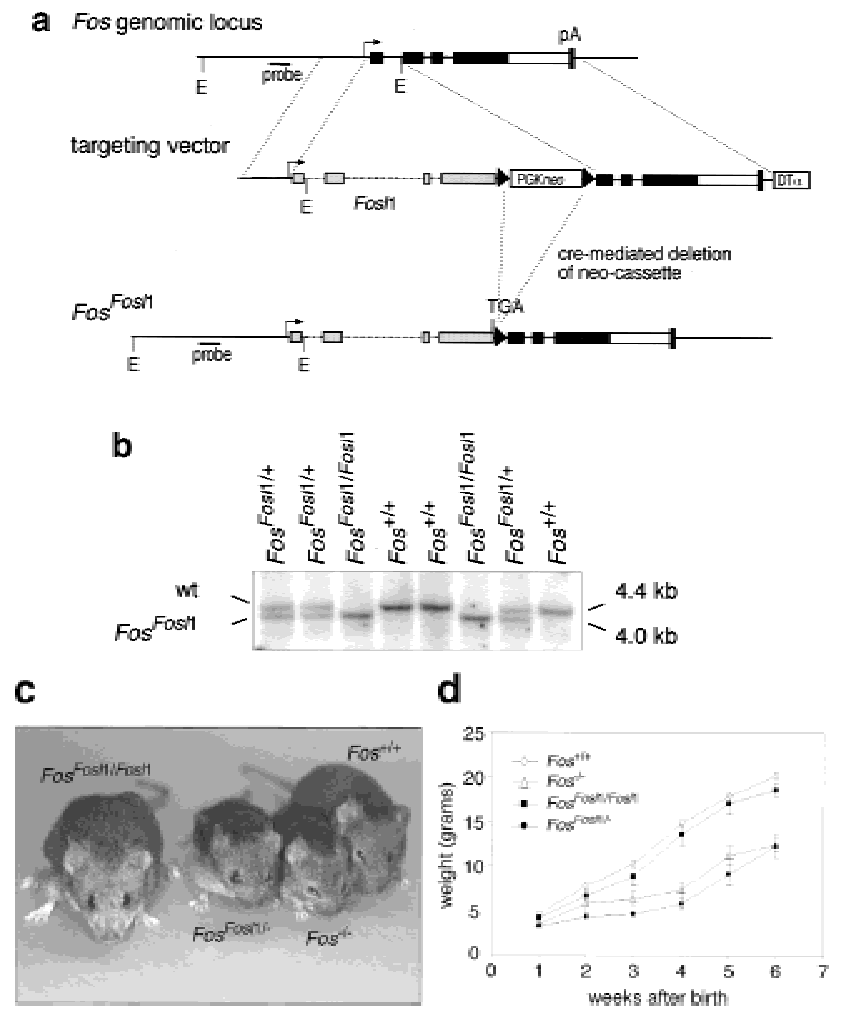

Figure 1. Generation of FoS ${ }^{F o s 11}$ knock-in mice. (a) Schematic representation of the targeting strategy. Exons are depicted as black (FOS) and gray (Fosl1) boxes; the open box before the Fos polyadenylation signal (pA) represents the 3' UTR. The targeted allele was obtained after homologous recombination and removal of the floxed PGKneo cassette in embryonic stem cells. The probe and EcoRI restriction sites (E) used for genotyping by Southern blot are indicated. loxP sites are represented by triangles. (DT $\alpha$ ) diphtheria toxin $\alpha$ gene. (b) Southern blot analysis of progeny from a Fos ${ }^{\text {Fos } 11 /+}$ heterozygous intercross. Genotypes are indicated, as well as the positions of the expected wild-type (wt) and knock-in bands. (c) Phenotypic appearence of $\mathrm{Fos}^{-/-}$, Fos ${ }^{\text {Fos11/Fosl1 }}$, and FOS ${ }^{\text {Fos } 11 /-}$ mice at 6 wk of age. Note the reduced size and shortened snout of $\mathrm{FOS}^{\mathrm{FO}} \mathrm{s11/-}$ and $\mathrm{FOS}^{-/-}$mice compared with wild-type and Fos ${ }^{\text {Fosl1/Fosl1 }}$ mice. (d) Postnatal growth of $\mathrm{FOS}^{+/+}$(wild-type) Fos ${ }^{-/-}$, Fos ${ }^{\text {Fos } 11 / F o s 11}$, and Fos ${ }^{\text {Fos } 11 /-}$ mice. Five females were scored per genotype, and each value represents the mean weight in grams \pm S.E.M. of the mean. Similar results were obtained with male mice (data not shown). cassette, ES cells were injected into mouse blastocysts, and two independent clones transmitted the targeted allele through the germ line. Fos ${ }^{\text {Fos } 11 /+}$ heterozygous mice were intercrossed or bred with $\mathrm{Fos}^{-/-}$mice to generate the Fos ${ }^{\text {Fosl1/Fosl1 }}$ and Fos Fosl1/- mice (Fig. 1b,c).

\section{Gene dosage-dependent rescue of c-Fos functions} during mouse development and bone cell differentiation

Whereas Fos heterozygous mice appear normal, homozygous mutants show reduced viability at birth. Surviving c-Fos-deficient pups are smaller and, most notably, lack tooth eruption. In contrast, homozygous Fos ${ }^{\text {Fos11/Fos11 }}$ mice were indistinguishable from their wild-type littermates in size and weight (Fig. 1c,d). Furthermore, tooth eruption occurred normally (data not shown). To test whether a reduction of expression levels of Fos 11 knock-in transcripts would result in any phenotype, we crossed the knock-in allele over a Fos null allele. Surprisingly, Fos ${ }^{\text {Fos } 11 /-}$ mice were growth retarded, lacked teeth, and were indistinguishable from $\mathrm{Fos}^{-/}$ mice (Fig. 1c,d).

c-Fos-deficient mice are osteopetrotic as the result of a cell-autonomous defect in osteoclast differentiation. They display shortened long bones, disorganized growth plates, and occlusion of bone marrow cavities with abundant bone and cartilage material. X-ray analysis of FoS ${ }^{\text {Fos } 11 / F o s 11 ~ k n o c k-i n ~ m i c e ~ s h o w e d ~ n o r m a l ~ b o n e ~ a r c h i-~}$ tecture similar to wild-type controls (Fig. 2a). In contrast, $\mathrm{FOS}^{-/-}$and Fos ${ }^{\text {Fosl1/- }}$ mice lacked bone marrow cavities and displayed highly radiodense bones indicative of osteopetrosis. Histological sections of femurs revealed the formation of a bone marrow cavity and normal organization of the growth plate in Fos ${ }^{\text {Fos 11/Fos11 knock-in mice }}$ (Fig. 2b,c). Importantly, histochemical staining for tartrate- resistant acid phosphatase (TRAP), a marker for osteoclasts, revealed the presence of TRAP-positive, multinucleated osteoclasts. Osteoclast numbers were comparable in wild-type and Fos Fos11/Fos11 femurs, whereas $\mathrm{FOS}^{-1-}$ and Fos ${ }^{\text {Fosl1/- }}$ bones were devoid of TRAP-positive cells (Fig. 2d). Hence, expression of Fra-1 in place of c-Fos rescues the bone phenotype of c-Fosdeficient mice, although a single knock-in allele is insufficient to rescue the osteopetrosis.

\section{The Fosl1 knock-in allele recapitulates} the expression pattern of endogenous Fos

To determine whether the Fosl1 knock-in allele was expressed as the endogenous Fos, we prepared RNA from various organs of a Fos ${ }^{\text {Fos11/+ }}$ heterozygous mouse. Ribonuclease (RNase) protection assay was performed using probes that distinguish between endogenous Fos, endogenous Fos11, and the Fosl1 knock-in transcript. Tissues such as brain and bone, which express high levels of endogenous Fos, expressed similarly high levels of Fosl1 knock-in transcripts, whereas tissues with low Fos levels showed low levels of the Fosl1 knock-in transcript (Fig. 3a). Importantly, expression levels of the knockin allele were independent of modifications on the second Fos locus: Fos11 knock-in levels were similar in bones of Fos ${ }^{\text {Fosl1/+ }}$ and Fos ${ }^{\text {Fosl1/- }}$ mice, and homozygous 


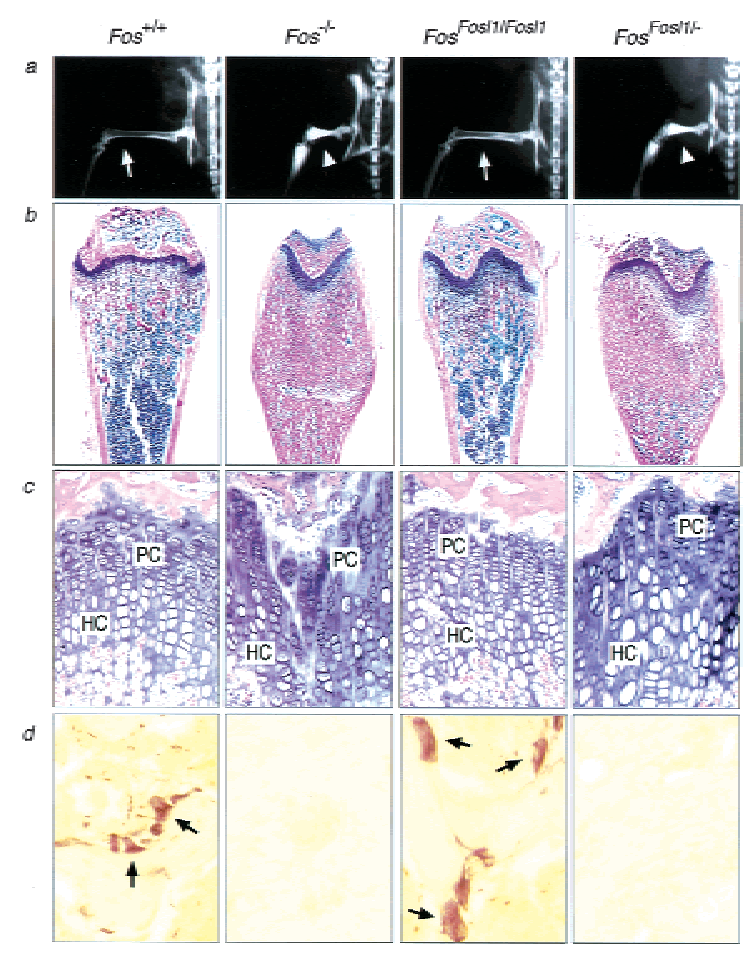

Figure 2. Gene dosage-dependent rescue of bone development in Fos ${ }^{F o s 11}$ knock-in mice. (a) X-ray analysis of femur and knee joint of 2-month-old mice of the indicated genotype. Note the normal bone marrow cavities in wild-type and Fos ${ }^{\text {Fos11/Fosl1 }}$ mice (arrows) compared with osteopetrotic bones of $\mathrm{Fos}^{-1-}$ and Fos ${ }^{\text {Fos } 11 /-}$ mice (arrowheads). (b) Histological sections of femurs. (c) High magnification of $b$ to show rescue of growth plate organization in Fos ${ }^{\text {Fos11/Fos11 }}$ bones. (HC) hypertrophic chondrocytes; (PC) proliferating chondrocytes. (d) TRAP-positive multinucleated osteoclasts (arrows) are present in femurs of wildtype and Fos Fos11/Fosl1 mice but absent in $\mathrm{FOS}^{-/-}$and Fos Fos11/mice.

Fos Fos11/Fos11 mice expressed approximately twice as many Fosl1 transcripts (Fig. 3b). The Fosl1 knock-in allele was highly overexpressed in comparison to endogenous Fosl1 (Fig. 3a), in agreement with previously reported observations showing that Fos expression is much higher than Fos11 expression in tissues of adult mice.

To analyze the temporal expression profile of the knock-in allele upon serum stimulation, we prepared primary mouse embryonic fibroblasts (MEFs) from wildtype and knock-in embryos. Cells were starved in low serum, and expression of FOS and Fosl1 was induced by the addition of $15 \%$ fetal calf serum (FCS). RNA was prepared at the indicated time points and analyzed by Northern blotting (Fig. 4a). As expected, high and transient expression of Fos was observed in wild-type fibroblasts at $1 \mathrm{~h}$ after serum stimulation. The Fos 11 knock-in allele displayed a similar expression profile, whereas endogenous Fosl1 was induced at later time points and transcripts were more stable. At the protein level, c-Fos was expressed at 1 and $2 \mathrm{~h}$ after stimulation in wild-type cells but, as expected, was not detectable in Fos Fos11/Fos11 cell extracts (Fig. 4b). Using an antibody that does not distinguish between endogenous and knock-in Fra-1, we were able to detect Fra-1 at low levels 2 to $6 \mathrm{~h}$ after stimulation in wild-type cells. In contrast, it was induced earlier and at higher levels in Fos ${ }^{\text {Fos11/Fos11 cells, }}$ again following the expression profile of c-Fos. Interestingly, levels of endogenous Fra-1 seemed to be reduced in

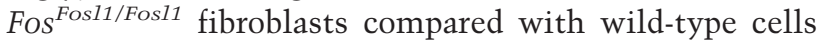
(Fig. 4a,b), suggesting that Fra-1 may not substitute for c-Fos in regulating its own expression.

\section{Fra-1 fails to induce expression of c-Fos target genes in fibroblasts}

A major difference between c-Fos and Fra-1 is their potential to transactivate expression of AP-1 target genes. To analyze whether Fra-1 could replace c-Fos in controlling c-Fos-dependent gene transcription, we generated 3T3-like fibroblasts in which Collagenase-1 (MMP-13) expression was shown to be c-Fos dependent ( $\mathrm{Hu}$ et al. 1994). Cells were starved and after stimulation with FCS RNA was prepared at various time points and analyzed using Northern blotting. In wild-type cells, collagenase- 1 was strongly induced at 4 and $8 \mathrm{~h}$ after stimulation, whereas, as reported previously, this response was abolished in c-Fos-deficient cells (Fig. 4c). Interestingly, induction of collagenase-1 expression was greatly reduced in Fos ${ }^{\text {Fos11/Fos11 }}$ cells, similar to c-Fos-deficient cells. We next examined the expression of the intermediate filament Vimentin, a transcriptional target of c-Fos (Reichmann et al. 1992). Induction of vimentin expression was reduced in c-Fos-deficient cells, and again, this deficiency was not rescued by the Fos 11 knock-in. In contrast, expression of Jun, a c-Fos-independent AP-1 target gene, was comparable between wild-type and mutant

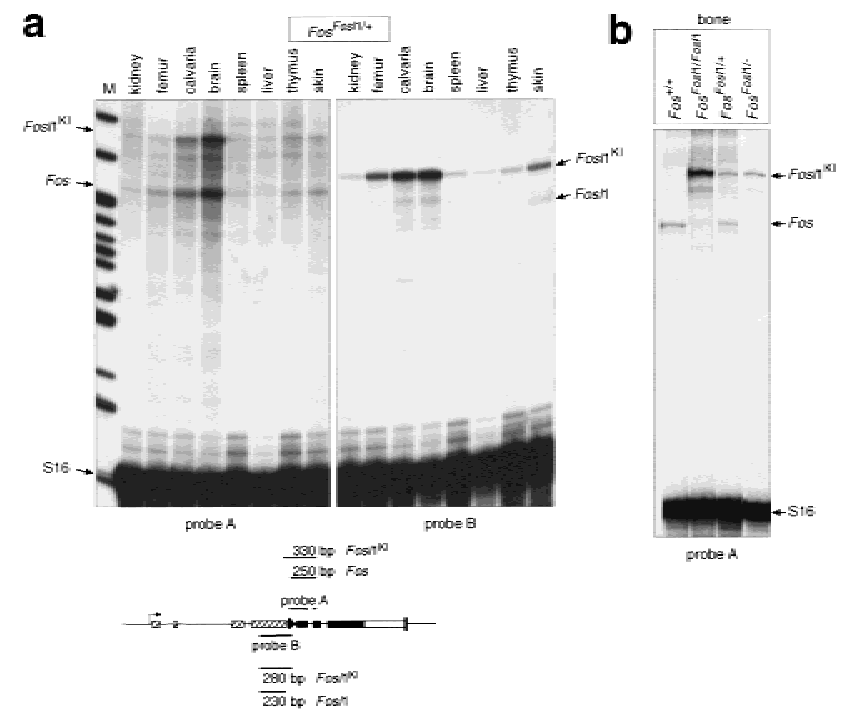

Figure 3. Expression of the Fos ${ }^{\text {Fos } 11}$ knock-in allele in mice. (a) RNase protection assay with RNA from various organs of a Fos ${ }^{\text {Fosi1/+ }}$ heterozygous mouse. Sizes of protected endogenous Fos, endogenous Fosl1, and Fosl1 knock-in (Fos $11^{\mathrm{KI}}$ ) transcripts are indicated by arrows. Probes are depicted schematically. (b) Expression of endogenous Fos and Fos 11 knock-in transcripts in bones of mice of the indicated genotype. (M) molecular mass marker; (S16) ribosomal RNA as loading control. 


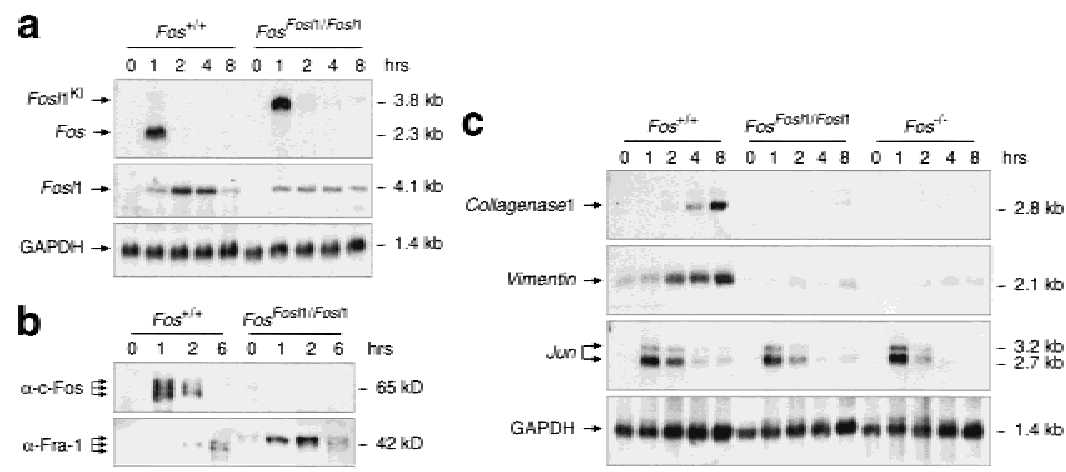

Figure 4. Expression of Fos, Fos11, and AP-1 target genes in fibroblasts. Cells were starved for $48 \mathrm{~h}$, stimulated with $15 \%$ FCS, and harvested at the indicated time points. (a) Northern blot analysis of RNA prepared from mouse embryonic fibroblasts (MEFs) of the indicated genotype. GAPDH expression served as a control for RNA loading. (b) Western blot analysis of nuclear extracts prepared from wild-type

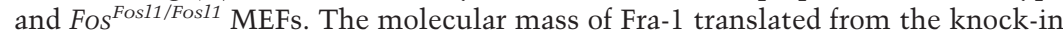
allele appears slightly larger than endogenous Fra-1 because of six additional amino acids at the $\mathrm{C}$ terminus, a result of the cloning strategy. (c) Northern blot analysis of AP-1 target genes in 3T3 fibroblasts. Northern blots were probed with probes specific for Collagenase-1, Vimentin, Jun, and GAPDH.

cells. These data indicate that Fra-1 cannot substitute for c-Fos in activating c-Fos-dependent target gene transcription in fibroblasts.

\section{Fra-1 substitutes for c-Fos in light-induced retinal} photoreceptor apoptosis

Next we investigated whether Fra-1 could substitute for the pro-apoptotic function of c-Fos in neuronal cells of the adult mouse. c-Fos is expressed in retinal neurons, is up-regulated during apoptotic cell death in retinal degenerations, and is essential for light induced-apoptosis (Hafezi et al. 1997; Wenzel et al. 2000). To induce retinal degeneration with apoptotic cell death of photoreceptor neurons, we exposed mice to high levels of white light and analyzed them at $7 \mathrm{~d}$ after exposure. As demonstrated by light microscopy and TUNEL staining, Fos ${ }^{\text {Fos } 11 / F o s 11}$ and Fos ${ }^{\text {Fos } 11 /-}$ mice showed extensive apoptosis after light exposure, comparable to that shown by wild-type controls (Fig. 5a,b). In contrast, c-Fos-deficient mice showed the expected resistance against light-induced cell death. These results indicate that Fra-1 can functionally replace c-Fos in photoreceptor cell apoptosis. In contrast to bone development, light-induced apoptosis does not appear to be sensitive to the levels of Fra-1 expression.

\section{Discussion}

Gene knock-out experiments of individual AP-1 proteins have greatly increased our understanding of their specific functions. However, it remains unclear to what extent AP- 1 subunits are redundant and can compensate for the lack of one individual gene product. To investigate whether Fra-1 could functionally substitute for c-Fos, we generated knock-in mice in which the Fos gene is disrupted and replaced by Fos11. Our results demonstrate that Fra-1 can fully complement for the lack of c-Fos in bone development, but surprisingly, the rescue was gene dosage dependent. The presence of a single knock-in allele and one Fos null allele resulted in osteopetrosis similar to that found in Fos knock-out mice, suggesting that osteoclast differentiation is sensitive to threshold levels of Fra-1. Interestingly, we observed signs of bone remodeling and few TRAP-positive osteoclasts in old FosFos11/- mice, suggesting that the block in osteoclast differentiation is not as complete as that found in Fos knock-out mice. Experiments using in vitro differentiation of osteoclast progenitors will provide further insight into the underlying molecular mechanism. The dosage effect was unexpected because deletion of a single allele of Fos or Fosl1 does not lead to phenotypic abnormalities in mice (Johnson et al. 1992; Wang et al. 1992; Schreiber et al. 2000). In fact, none of the individual targeted deletions of AP-1 genes reported so far has resulted in disorders in the heterozygous state (Hilberg et al. 1993; Johnson et al. 1993; Brown et al. 1996; Gruda et al. 1996; Schorpp-Kistner et al. 1999; Thepot et al. 2000).

Surprisingly, ectoptic expression of Fosl1 in Fosl1 knock-in mice did not result in any novel phenotypes, nor did it recapitulate the osteosclerotic phenotype of Fosl1 and $\triangle F O S B$ transgenic mice (Jochum et al. 2000; Sabatakos et al. 2000). However, Fosl1 transgenic mice express Fosl1 under the control of the MHC class I promoter, which results in constitutive expression independent of growth factor stimulation. Furthermore, the levels of Fos11 expression were much higher in Fosl1 transgenic mice than in Fosl1 knock-in mice. In bone, which is the primarily affected tissue of Fosl1 transgenic mice, Fos11 expression was five- to 10-fold higher in transgenic than in knock-in mice (data not shown). Therefore, differences in the regulation and levels of expression of Fra-1 are likely to account for the distinct phenotypes of Fos11 transgenic and Fos ${ }^{F o s 11}$ knock-in mice. Because a major difference between c-Fos and Fra-1 is their role in tumorigenesis (Rüther et al. 1987; Wang et al. 1991; Jochum et al. 2000), it will be important to test whether replacement of c-Fos by Fra-1 alters AP-1-dependent tumor formation. Preliminary data with 3T3 fibroblasts indicate that knock-in fibroblasts can be transformed by $\mathrm{v}$-Ras and v-Src similar to wild-type controls, suggesting that expression of Fra-1 in place of c-Fos does not inhibit transformation by Ras and Src oncoproteins.

In the eye, lack of c-Fos has no major effects on retinal development albeit a moderate reduction of electrophysiological responses and photoreceptor number (Kueng-Hitz et al. 2000). Fos Fosl1/Fosl1 and Fos ${ }^{\text {Fosl1/- }}$ mice show apparently unimpaired retinal morphology; however, further studies are needed to investigate whether subtle functional and molecular changes have occurred. Our observations suggest that expression of Fra-1 in place of c-Fos has no strong impact on developmental photoreceptor apoptosis. In contrast, light-induced photoreceptor apoptosis in adult mice is strictly c-Fos de- 


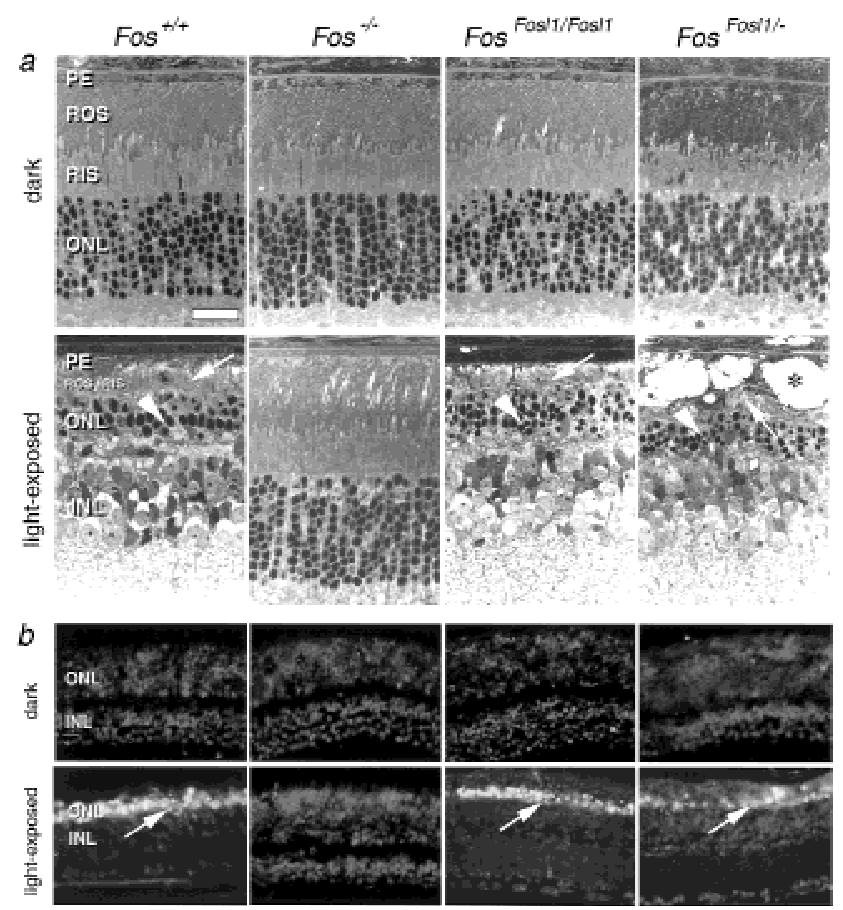

Figure 5. Gene dosage-independent rescue of photoreceptor apoptosis in Fos ${ }^{\text {Fosl1 }}$ knock-in mice. (a) Light microscopic analysis of retinal apoptosis. Dark-adapted mice of all genotypes show comparable and regular retinal morphology. Analysis at 7 d after light exposure shows complete disintegration of rod outer segment (ROS) and rod inner segment (RIS) disks (arrows) and a distinctly thinned outer nuclear layer (ONL) with only a few remaining condensed photoreceptor nuclei (arrowheads) in $\mathrm{FOS}^{+/+}$, Fos ${ }^{\text {Fosl1/Fosl1 }}$, and Fos ${ }^{\mathrm{Fos} 11 /-}$ mice. In contrast, the retinas of $\mathrm{FOS}^{-1-}$ mice are unaffected. Fos ${ }^{\mathrm{Fos} 11 /-}$ mice show areas of cystic vesiculation of cells of the pigmented epithelium (PE; asterisk) and an accumulation of phagocytic cells. Such changes are occasionally observed after light exposure and are not related to the genotype. $(b)$ TUNEL assay. Retinas of dark-adapted mice of all genotypes do not show labeling. Analysis at $7 \mathrm{~d}$ after light exposure shows labeling of photoreceptor nuclei in the ONL in $\mathrm{FOS}^{+/+}$, FOS ${ }^{\mathrm{Fos} 11 / \mathrm{Fosl1}}$, and Fos ${ }^{\mathrm{Fos} 11 /-}$ mice. Retinas of $\mathrm{FOS}^{-/-}$mice are devoid of apoptotic cells. (INL) inner nuclear layer. Scale, $25 \mu \mathrm{m}$.

pendent and was rescued by expression of Fra-1. Notably, under our experimental conditions, apoptosis was not sensitive to Fra-1 threshold levels because Fos Fosl1/mice show massive photoreceptor apoptosis comparable to the degeneration observed in Fos ${ }^{\text {Fos11/Fos } 11}$ and wildtype mice. It remains to be tested, however, whether the threshold for apoptosis induction by light and the time course of the apoptotic response differ from the ones observed in wild-type mice.

In this study, we show that Fra-1 can functionally substitute for the lack of c-Fos in mice. Functional redundancy has recently been reported for other gene families, either for structurally highly homologous genes (Hanks et al. 1995; Malynn et al. 2000) or for genes functioning in a linear pathway (Wang et al. 1996; Geng et al. 1999). Our finding is particularly surprising in view of previous studies demonstrating that Fra- 1 and c-Fos proteins are as different in their biochemical properties. Consistent with these data, we show that the Fra-1 knock-in fails to rescue expression of c-Fos target genes in vitro. However, Fra-1 can fully take over c-Fos-dependent functions in vivo. Several explanations could be envisaged to explain the molecular basis of the observed rescue. First, c-Fos could exert its function by solely activating Fra-1, which in turn regulates the expression of downstream target genes. Thus, Fra- 1 would be the only biologically important transcriptional target of c-Fos. This hypothesis is unlikely for various reasons, including their largely nonoverlapping expression patterns and the distinct phenotypes of Fosl1 and Fos knock-out and transgenic mice. Second, it is possible that Fra- 1 acts as a transcriptional activator, similar to c-Fos, in a cell-type specific manner in vivo. However, this is in conflict with the generally accepted view of Fra-1 as a weak transactivator and the lack of autonomous transactivation domains. Therefore, we favor a third model in which both Fra-1 and c-Fos would exert their functions as adaptors for other transcription factors or even act as transcriptional repressors. This hypothesis is substantiated by the fact that aside from the dimerization and DNA-binding domain, the only highly conserved region between c-Fos and Fra- 1 is a putative transrepression domain at the $\mathrm{C}$ terminus. To verify this hypothesis, we have initiated a microarraybased screen to identify essential c-Fos and Fra-1 target genes in the relevant cell types. Our data have clearly shown that c-Fos and Fra-1 maintained functional equivalence during vertebrate evolution and suggest that functional diversity of Fos genes is a result of divergence of regulatory rather than protein-coding sequences.

\section{Materials and methods}

Generation of Fos ${ }^{\text {Fosll }}$ knock-in mice

We excised $1.1 \mathrm{~kb}$ of the Fos promoter and $2.7 \mathrm{~kb}$ of $3^{\prime}$ homologous sequences from clone C49/105 (Wang et al. 1992) as SacI-SacII and NheIBamHI fragments, respectively, and cloned them into pBluescript. A 7.4kb SacII-NotI fragment containing the entire Fosl1 gene without 3' regulatory sequences was inserted at position -60 relative to the Fos translation initiation codon. A floxed PGKneo cassette and the diphtheria toxin $\alpha$ gene $(\mathrm{DT} \alpha)$ were used to select for homologous recombinants. The construct was electroporated into E14.1 ES cells, and out of 400 clones analyzed, three correctly targeted clones were identified by PCR and Southern blot analysis. The PGKneo selection cassette was removed in vitro by transient expression of Cre-recombinase. Transcripts from the knock-in allele contain the entire Fosl1 coding region. Six additional amino acids were added to the Fra- $1 \mathrm{C}$ terminus as a result of the cloning strategy, followed by two translation stop codons. The remaining Fos sequences are out of frame, and no aberrant splice products were detectable by reverse transcriptase-PCR using various primer combinations (data not shown). Chimeric mice were generated by injecting ES cell clones into $\mathrm{C} 57 \mathrm{BL} / 6$ blastocysts, and germ line transmission was obtained from two independent clones. Mice were generated in 129 Sv, C57BL/6, and mixed genetic backgrounds, and no strain dependence of the phenotype was observed.

Southern blot, Northern blot, and ribonuclease protection assay For genotyping by Southern blot, a 900-bp AatII-PvuII fragment of the Fos promoter was used as a probe. Total RNA was isolated using the TRIzol reagent (GIBCO BRL). Probes for RNase protection were cloned into SP64 plasmids. RNase protection assays and Northern blots were performed according to standard procedures. A 400-bp fragment of the Fos11 3' UTR that is not present in Fosl1 knock-in transcript was used specifically to detect expression of endogenous Fos11. Results were confirmed using the full-length Fos 11 cDNA as a probe.

Western blot analysis

Nuclear protein extracts were prepared according to standard procedures. Protein $(20 \mu \mathrm{g})$ was separated by $10 \%$ SDS-PAGE and transferred onto 
PVDF filters (Millipore). The anti-c-Fos antibody was purchased from Santa Cruz (catalog no. sc-253), and the anti-Fral antibody was a gift from D. Lallemand and M. Yaniv (Pasteur Institute, Paris).

$X$-ray analysis and histological methods

Radiographic studies were performed with a soft X-ray machine (mammo DIAGNOST S, Philips). For histology, bones were fixed in $4 \%$ paraformaldehyde and then demineralized, dehydrated, and embedded in paraffin. Sections $5 \mu \mathrm{m}$ thick were stained with hematoxylin and eosin. For identification of osteoclasts, sections were stained for TRAP in the presence of $0.1 \mathrm{M}$ sodium tartrate.

\section{Analysis of photoreceptor apoptosis}

The pupils of dark-adapted animals were dilated in dim red light with $1 \%$ cyclogyl and 5\% phenylephrine before exposure for $2 \mathrm{~h}$ to 15,000 lux of diffuse white fluorescent light. After light exposure, animals remained in darkness for $7 \mathrm{~d}$ until analyzed. For light microscopy, enucleated eyes were fixed in $2.5 \%$ glutaraldehyde, and eyecups were embedded in Epon 812. TUNEL assay was performed on paraffin-embedded sections using the in situ cell death detection kit (Boehringer Mannheim).

\section{Cell culture}

MEFs were prepared from E12.5 embryos and cultured in Dulbecco's modified Eagle's medium containing 10\% FCS. Immortalized 3T3-like fibroblasts were established, as described by Schreiber et al. (2000). At least two independently derived cell lines of each genotype were analyzed.

\section{Acknowledgments}

We thank H.-C. Theussl for blastocyst injections, U. Möhle-Steinlein for help with ES cell culture, H. Tkadletz for help with graphics, A. Bichl for maintaining our mouse colony, D. Lallemand and $\mathrm{M}$. Yaniv for providing anti-Fra-1 antibodies, and M. Sibilia, M. Baccarini, G. Christofori, K. Matsuo, E. Passegué, M. Schreiber, and A. Grigoriadis for helpful discussion and critical reading of the manuscript. Work in E.F.W.'s lab was supported by Boehringer Ingelheim, the Austrian Industrial Research Promotion Fund (FFF), and the Austrian Research Foundation (FWF).

The publication costs of this article were defrayed in part by payment of page charges. This article must therefore be hereby marked "advertisement" in accordance with 18 USC section 1734 solely to indicate this fact.

\section{References}

Angel, P. and Karin, M. 1991. The role of Jun, Fos and the AP-1 complex in cell-proliferation and transformation. Biochem. Biophys. Acto 1072: $129-157$.

Bergers, G., Graninger, P., Braselmann, S., Wrighton, C., and Busslinger, M. 1995. Transcritional activation of the fra- 1 gene by AP-1 is mediated by regulatory sequences in the first intron. Mol. Cell. Biol. 15: $3748-3758$

Brown, J.R., Ye, H., Bronson, R.T., Dikkes, P., and Greenberg, M.E. 1996 A defect in nurturing in mice lacking the immediate early gene fosB. Cell 86: 297-309.

Cohen, D.R. and Curran, T. 1988. fra-1: A serum-inducible, cellular immediate-early gene that encodes a fos-related antigen. Mol. Cell. Biol. 8: 2063-2069.

Cohen, D.R., Ferreira, P.C., Gentz, R., Franza, B.R., Jr., and Curran, T. 1989. The product of a fos-related gene, fra-1, binds cooperatively to the AP-1 site with Jun: Transcription factor AP-1 is comprised of multiple protein complexes. Genes \& Dev. 3: 173-184.

Geng, Y., Whoriskey, W., Park, M., Bronson, R.T., Medema, R.H., Li, T., Weinberg, R. A., and Sicinski, P. 1999. Rescue of cyclin D1 deficiency by knockin cyclin E. Cell 97: 767-777.

Grigoriadis, A.E., Wang, Z.-Q., Cecchini, M.G., Hofstetter, W., Felix, R., Fleisch, H.A., and Wagner, E.F. 1994. c-Fos: A key regulator of osteoclast-macrophage lineage determination and bone remodeling. Science 266: 443-448.

Gruda, M.C., van Amsterdam, J., Rizzo, C.A., Durham, S.K., Lira, S., and Bravo, R. 1996. Expression of FosB during mouse development: Normal development of FosB knock-out mice. Oncogene 12: 2177-2185.

Hafezi, F., Steinbach, J.P., Marti, A., Munz, K., Wang, Z.-Q., Wagner, E.F., Aguzzi, A., and Remé, C.E. 1997. The absence of c-fos prevents lightinduced apoptotic cell death of photoreceptors in retinal degeneration in vivo. Nat. Med. 3: 346-349.

Hanks, M., Wurst, W., Anson-Cartwright, L. Auerbach, A.B., and Joyner, A.L. 1995. Rescue of En-1 mutant phenotype by replacement of En-1 with En-2. Science 269: 679-682.

Hilberg, F., Aguzzi, A., Howells, N., and Wagner, E.F. 1993. c-jun is essential for normal mouse development and hepatogenesis. Nature 365: 179-181.

Hu, E., Mueller, E., Oliviero, S., Papaioannou, V.E., Johnson, R., and Spiegelmann, B.M. 1994. Targeted disruption of the c-fos gene demonstrates c-fos-dependent and -independent pathways for gene expression stimulated by growth factors or oncogenes. EMBO $\mathrm{T}$. 13: 3094-3103.

Jochum, W., David, J.P., Elliott, C., Wutz, A., Plenk, H., Matsuo, K., and Wagner, E.F. 2000. Increased bone formation and osteosclerosis in mice overexpressing the transcription factor Fra-1. Nat. Med. 6: 980-984.

Johnson, R.S., Spiegelman B.M., and Papaioannou, V. 1992. Pleiotropic effects of a null mutation in the c-fos proto-oncogene. Cell 71: 577-586.

Johnson, R.S., van Lingen, B., Papaioannou, V., and Spiegelmann, B.M. 1993. A null mutation at the c-jun locus causes embryonic lethality and retarded cell growth in culture. Genes \& Dev. 7: 1309-1317.

Karin, M., Zhend-gang, L., and Zandi, E. 1997. AP-1 function and regulation. Curr. Opin. Cell. Biol. 9: 240-246.

Kueng-Hitz, N., Grimm, C., Lansel, N., Hafezi, F., He, L., Fox, D.A., Remé, C.E., Niemeyer, G., and Wenzel, A. 2000. The retina of c-fos-/- mice: Electrophysiologic, morphologic and biochemical aspects. Invest. Ophthalmol. Vis. Sci. 41: 909-916.

Malynn, B.A., de Alboran, I.M., O'Hagan, R., Bronson, R., Davidson, L., DePinho, R.A., and Alt, F.W. 2000. N-myc can functionally replace c-myc in murine development, cellular growth, and differentiation. Genes \& Dev. 14: 1390-1399.

Matsuo, K., Ownes, J.M., Tonko, M., Elliott, C., Chambers, T.J., and Wagner, E.F. 2000. Fosll is a transcriptional target of c-Fos during osteoclast differentiation. Nat. Genet. 24: 184-187.

Reichmann, E., Schwarz, H., Deiner, E.M., Leitner, J., Eilers, M., Berger J., Busslinger, M., and Beug, H. 1992. Activation of an inducible cFosER fusion protein causes loss of epithelial polarity and triggers epithelial-fibroblastoid cell conversion. Cell 7: 1103-1116.

Rüther, U., Garber, C., Komitowski, D., Müller, R., and Wagner, E.F. 1987. Deregulated c-fos expression interferes with normal bone development in transgenic mice. Nature 325: 412-416.

Sabatakos, G., Sims, N.A., Chen, J., Aoki, K., Kelz, M.B., Amling, M., Bouali, Y., Mukhopadhyay, K., Ford, K., and Nestler, E.J., et al. 2000 The transcrition factor $\triangle \mathrm{FosB}$ promotes bone formation and inhibits adipogenesis. Nat. Med. 6: 985-990.

Schorpp-Kistner, M., Wang, Z.-Q., Angel, P., and Wagner, E.F. 1999. JunB is essential for mammalian placentation. EMBO J. 18: 934-948.

Schreiber, M., Poirier, C., Franchi, A., Kurzbauer, R., Guenet, J.L., Carle, G.F., and Wagner, E.F. 1997. Structure and chromosomal assignment of the fra- 1 gene, and its exclusion as a candidate gene for oc (osteosclerosis). Oncogene 15: 1171-1178.

Schreiber, M., Wang, Z.-Q., Jochum, W., Fetka, I., Candace, E., and Wagner, E.F. 2000. Plancental vascularisation requires the AP-1 component Fra-1. Development (in press).

Smeyne, R.J., Vendrell, M., Hayward, M., Baker, S.J., Miao, G.G., Schilling, K., Robertson, L.M., Curran, T., and Morgan, J.I. 1993. Continuous c-fos expression precedes programmed cell death in vivo. Nature 363: 166-169.

Thepot, D., Weitzman, J.B., Barra, J., Segretain, D., Stinnakre, M.-G., Babinet, C., and Yaniv, M. 2000. Targeted disruption of the murine junD gene results in multiple defects in male reproductive function. Development 127: 143-153

Wang, Y., Schnegelsberg, P.N.J., Dausman, J., and Jaenisch, R. 1996. Functional redundancy of the muscle-specific transcription factors Myf5 and myogenin. Nature 379: 823-825.

Wang, Z.-Q., Grigoriadis, A.E., Möhle-Steinlein, U., and Wagner, E.F. 1991. A novel target for c-fos-induced oncogenesis: Development of chondrogenic tumours in embryonic stem cell chimeras. EMBO J. 10: $2437-2450$.

Wang, Z.-Q., Ovitt, C., Grigoriadis, A.E., Möhle-Steinlein, U., Rüther, U., and Wagner, E.F. 1992. Bone and hematopoetic defects in mice lacking c-fos. Nature 360: 741-745.

Wenzel, A., Grimm, C., Marti, A., Kueng-Hitz, N., Hafezi, F., Niemeyer, G., and Remé, C.E. 2000. c-fos controls the "private pathway" of light-induced apoptosis of retinal photoreceptors. J. Neurosci. 20: 81-88.

Yoshioka, K., Deng, T., Cavigelli, M., and Karin, M. 1995. Antitumor promotion by phenolic antioxidants: Inhibition of AP-1 activity through induction of Fra expression. Proc. Nat1. Acad. Sci. 92: 4972-4976. 


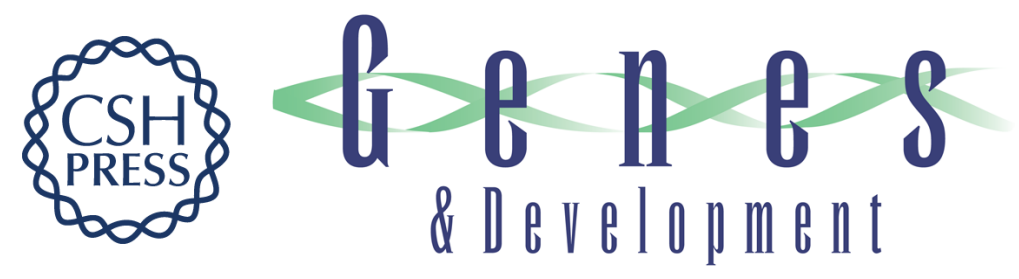

\section{Fra-1 replaces c-Fos-dependent functions in mice}

Alexander Fleischmann, Farhad Hafezi, Candace Elliott, et al.

Genes Dev. 2000, 14:

Access the most recent version at doi:10.1101/gad.187900

References This article cites 30 articles, 12 of which can be accessed free at: http://genesdev.cshlp.org/content/14/21/2695.full.html\#ref-list-1

License

Email Alerting Receive free email alerts when new articles cite this article - sign up in the box at the top Service right corner of the article or click here.

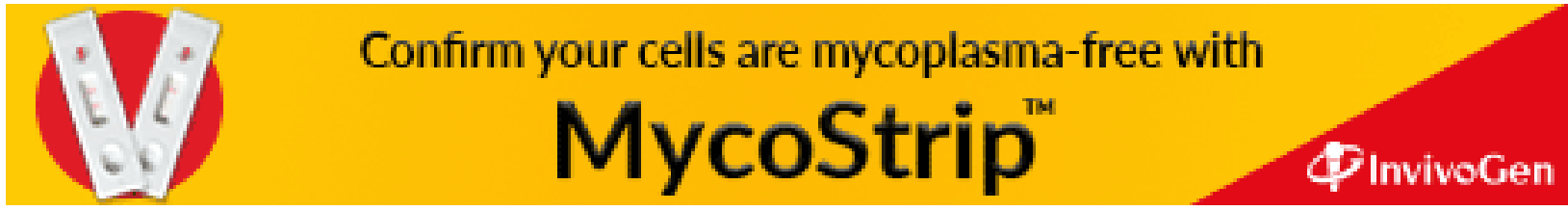

